\title{
Proceedings of the 2009 MidSouth Computational Biology and Bioinformatics Society (MCBIOS) Conference
}

\author{
Jonathan D Wren*1, Yuriy Gusev ${ }^{2}$, Raphael D Isokpehi ${ }^{3}$, Daniel Berleant ${ }^{4}$, \\ Ulisses Braga-Neto ${ }^{5}$, Dawn Wilkins ${ }^{6}$ and Susan Bridges ${ }^{7}$
}

\begin{abstract}
Address: ${ }^{1}$ Arthritis and Immunology Research Program, Oklahoma Medical Research Foundation; 825 N.E. 13th Street, Oklahoma City, OK 73104-5005, USA, ${ }^{2}$ Department of Surgery, Health Sciences Center, The University of Oklahoma, Oklahoma City, OK 73104, USA, ${ }^{3}$ College of Science, Engineering and Technology, Jackson State University, Jackson, MS, USA, ${ }^{4}$ Department of Information Science, University of Arkansas at Little Rock, Little Rock, AR 72204, USA, ${ }^{5}$ Department of Electrical and Computer Engineering, Texas A\&M University, College Station, 77843-3128, USA, ${ }^{6}$ Computer \& Information Science Department, The University of Mississippi, University, MS 38677, USA and ${ }^{7}$ Department of Computer Science and Engineering, Mississippi State University, Box 9637, Mississippi State, MS 39762, USA
\end{abstract}

E-mail: Jonathan D Wren* - jdwren@gmail.com; Yuriy Gusev - Yuriy-Gusev@ouhsc.edu; Raphael D Isokpehi - raphael.isokpehi@jsums.edu; Daniel Berleant - berleant@gmail.com; Ulisses Braga-Neto - ulisses@ece.tamu.edu; Dawn Wilkins - dwilkins@cs.olemiss.edu;

Susan Bridges - bridges@cse.msstate.edu

*Corresponding author

from Sixth Annual MCBIOS Conference. Transformational Bioinformatics: Delivering Value from Genomes

Starkville, MS, USA 20-21 February 2009

Published: 08 October 2009

BMC Bioinformatics 2009, I0(SuppI II):SI doi: 10.II86/I47I-2105-I0-SII-SI

This article is available from: http://www.biomedcentral.com/I47I-2/05/I0/SII/SI

(c) 2009 Wren et al; licensee BioMed Central Ltd.

This is an open access article distributed under the terms of the Creative Commons Attribution License (http://creativecommons.org/licenses/by/2.0), which permits unrestricted use, distribution, and reproduction in any medium, provided the original work is properly cited.

\section{Introduction}

MCBIOS 2009 was held February 20-21, 2009 at the Hunter Henry Center in Starkville, Mississippi on the Mississippi State University campus. The conference was hosted by the four research universities in Mississippi comprising the Mississippi Computational Biology Consortium - Jackson State University (JSU), Mississippi State University (MSU), the University of Mississippi (UM), and the University of Southern Mississippi (USM). Dr. Dawn Wilkins of UM and Dr. Susan Bridges of MSU served as conference co-chairs. Keynote speakers were Dr. Laura Elnitski, Head of the Genomic Functional Analysis Section at the National Human Genome Research Institute (NHGRI), Howard Cash, President and CEO of Gene Codes Corporation, and Dr. Cathy $\mathrm{Wu}$, Director of the Protein Information Resource (PIR).

Dr. Raphael Isokpehi of JSU organized a panel discussion entitled Careers in Computational Biology and Bioinformatics: Perspective from Employers and Students. Panelists were Dr. Ed Perkins of the U.S. Army
Engineering Research and Development Center, Robert Cottingham of Oak Ridge National Laboratory (ORNL), Dr. Doris M. Kupfer, Federal Aviation Administration, James C. Fuscoe, FDA National Center for Toxicological Research, and Cynthia Jeffries, student intern at ORNL. Over 40 student and faculty attendees also participated in the Speed Networking event organized by Dr. Isokpehi and featured in a recent Science Careers article [1]. Each person in the event spent 3 minutes talking to twenty other participants in the two hour session providing students an opportunity to interact with employers and with students from other universities in the region.

Dr. Bindu Nanduri and Dr. Andy Perkins, both of MSU managed the setup, judging, and scoring of 80 posters. Monetary awards were provided by Dr. Ed Perkins. Student poster award winners were: first place - Eric Morales of the University of New Orleans (UNO), second place Teresia Buza of MSU, third place Prashanti Manda of MSU and honorable mention to 
Amanda Alba of the UNO, Surya Saha of MSU and Sudhir Chowbina of the Indiana University School of Informatics. Student winners for oral presentations were: first place - Enis Afgan of the University of Alabama at Birmingham, second place - Lipi R. Archarya of UNO, and third place - Anastasia Chueva of Mississippi Valley State University.

\section{Proceedings summary}

Thirty-two papers from the 2009 conference were submitted to be considered for inclusion in this supplement, and of them a total of 20 were accepted (62.5\% accept rate), making this year's Proceedings the most stringent to date. The number of submitted papers exceeded that of the 2008 MCBIOS Proceedings [2-20]. As in prior conferences, we strove to be inclusive yet rigorous in the peer-review process, so that the end result is both high quality and reflective of the work presented. Papers generally fell into five categories:

\section{Systems biology}

A means of better understanding how systems work and interconnect as opposed to the traditional approach of isolating subcomponents and focusing on them is called Systems Biology and has become an increasingly active area of study in bioinformatics [21-34]. Andrey Ptitsyn offers a systems biology approach to the analysis of microarray data [35], partitioning gene expression space into a multi-dimensional taxonomy. Differences between "taxa" are then studied using biological pathway analysis software to associate gene expression patterns with specific phenotypes. For example, the application identifies a link between glycine metabolism aberrations and metabolic biomarkers for metastatic prostate cancer.

Gao et al. [36] describe an approach to better integrate data from disparate sources to reach better conclusions about biological response to stimulus than could be obtained from any of the component sources alone. Their study combined the Gene Ontology (GO) with microarray data using a bigraph data structure and associated algorithms.

Chowbina et al. address data integration from a different perspective[37], describing a technical resource for regulatory, signaling and biochemical reactions in human biomolecular pathways. Their resource, Human Pathway Database (HPD), integrates several existing resources to provide a web interface to access approximately one thousand pathways.

Zhang et al. present text empirics in the context of the PathBinder system [38]. Text empirics refers to properties of texts that are derived by examining the texts themselves. It differs from the machine learning approach in that derived properties are manually curated and presented as facts that system builders can use when they are designing their systems.

\section{OMICS}

"OMICS" is a broad category, based on the fact that fields of study for biological entities often end with the suffix "omics" (e.g., transcriptomics, proteomics) [39-45]. Pendarvis et al. [46] describe the creation of a workflow system to analyze mass spectrometry replicate datasets to generate a list of identified proteins and expression changes and link them to biological knowledge. Because it is compliant with proteomic data submission guidelines, users can readily publish data to public proteomic data repositories.

Mete et al. [47] present a novel digital image analysis approach to the automated evaluation of angiogenesis in Liver Cancer. The method identifies regional, morphological and fractal features and helps measure microvessel density on digitized images of liver tumor sections. Their results show agreement between automated calculations and manual counting of microvessels.

\section{Microarray studies}

Microarrays have long been a subject of bioinformatics analysis not only for better understanding transcription, but also as a model for large-scale analysis of genetic behavior [48-56]. Van Den Berg et al. compared gene annotation enrichment tools for functional modeling of agricultural microarray data [57], a category that is underrepresented among current tools. Chavan et al. describe Network Analysis Toolbox in R (NATbox), which provides a menu-driven GUI for modeling and analysis of functional relationships inferred from gene expression profiles. It is suited for interdisciplinary researchers and biologists with minimal programming experience who would like to use systems biology approaches without delving into the algorithmic aspects, and can be a useful demonstration/teaching tool.

Perkins and Langston [59] identify a means of effectively selecting thresholds for gene expression on microarrays by identifying "cliques" or subgroups of co-expressed genes. Roughly, the idea being that individual measurements are prone to error, but when a gene is seen coexpressed with other genes, then this reinforces the validity of the expression being biologically significant.

Li et al. [60] investigate inter- and intra-platform consistency of microarray measurements. Using pathway 
data as a guide for identifying biologically consistent results, the authors demonstrate that highly consistent biological information can be generated from different microarray platforms.

\section{Genomic analysis}

T.J. Jankun-Kelly and colleagues present a method to visually explore conserved domains on Multiple Sequence Alignments [61], simultaneously communicating the relative similarity of proteins across species and the differences in how function is expressed via conserved domains. It quickly identifies conserved domains and allows both macro (sequence-long) and micro (small amino-acid neighborhood) views.

$\mathrm{Xu}$ et al. [62] report the results of an extensive comparative genomics analysis of plant lignin biosynthesis gene families. Lignin is a major component of plant cell walls and appears to be the major cause of cell wall recalcitrance in energy production. Their analysis confirms that, among the species analyzed, the first complete lignin biosynthesis pathway appeared in moss. The major expansion of biosynthesis families occurred after the divergence of monocots and dicots and duplicated genes had many different fates. They conclude that transgenic lignin modification strategies to bioenergy feedstock may only be successful between closely related species.

T. Buza et al. report a method of automated functional annotation of the chicken genome, improving both the breadth and quality of annotation of genes [63]. The method can facilitate functional annotation of other microarrays via an Array GO Mapper (AGOM) tool to help researchers quickly retrieve corresponding functional information.

Zhou et al. [64] develop CPTRA (Cross-Platform Transcriptome Analysis) to analyze Next Generation Sequencing based on Transcriptome profiling in species with limited genome information.

\section{Miscellaneous}

Garcia-Reyero et al. [65] study gene expression in fathead minnows (Pimephales promelas) in well-characterized sites adjacent to sewage treatment plants and find short-term exposure to effluents were able to induce a site-specific gene expression pattern in the fathead minnow gonad and liver and to affect fish sexual behavior.

There are several other papers published in the supplement but, for space, are not summarized here: Chen and
Johnson [66], Bright et al. [67], Zollanvari et al. [68] and Malone et al. [69].

\section{Future meetings}

MCBIOS 2010 will be held in Jonesboro, Arkansas, and hosted by Arkansas State University and the Arkansas Biosciences Institute. Daniel Berleant of University of Arkansas at Little Rock is the 2009-2010 President of MCBIOS and will be chair of MCBIOS 2010. Ulisses Braga-Neto of Texas A\&M University is the new President-elect of the society. See http://www.MCBIOS. org for information regarding MCBIOS and future meetings. MCBIOS is a regional affiliate of the International Society for Computational Biology http://www. ISCB.org.

\section{Competing interests}

The authors declare that they have no competing interests.

\section{Authors' contributions}

All authors served as co-editors for these proceedings, with JDW serving as Senior Editor. All authors helped write this editorial.

\section{Acknowledgements}

We would like to thank the Mississippi NSF EPSCoR for providing support for keynote speakers and the hard work of the peer-reviewers to help produce this supplement.

This article has been published as part of BMC Bioinformatics Volume 10 Supplement 1I, 2009: Proceedings of the Sixth Annual MCBIOS Conference. Transformational Bioinformatics: Delivering Value from Genomes. The full contents of the supplement are available online at http://www.biomedcentral.com/I47I-2/05/I0?issue=SII.

\section{References}

I. Holmes L: Perspective: Speed Networking for Scientists. Science Careers 2009.

2. Bottoms $C A$ and $X u$ D: Wanted: unique names for unique atom positions. PDB-wide analysis of diastereotopic atom names of small molecules containing diphosphate. BMC Bioinformatics 2008, 9(Suppl 9):SI6.

3. Chae M, Shmookler Reis RJ and Thaden JJ: An iterative blockshifting approach to retention time alignment that preserves the shape and area of gas chromatography-mass spectrometry peaks. BMC Bioinformatics 2008, 9(Suppl 9):SI 5 .

4. Churbanov $A$ and Winters-Hilt $S$ : Clustering ionic flow blockade toggles with a mixture of HMMs. BMC Bioinformatics 2008, 9(Suppl 9):SI3.

5. Dozmorov MG, Kyker KD, Hauser PJ, Saban R, Buethe DD, Dozmorov I, Centola MB, Culkin DJ and Hurst RE: From microarray to biology: an integrated experimental, statistical and in silico analysis of how the extracellular matrix modulates the phenotype of cancer cells. BMC Bioinformatics 2008, 9(Suppl 9):S4.

6. Frank RL, Kandoth $C$ and Ercal F: Validation of an NSP-based (negative selection pattern) gene family identification strategy. BMC Bioinformatics 2008, 9(Suppl 9):S2

7. Giles $C B$ and Wren JD: Large-scale directional relationship extraction and resolution. BMC Bioinformatics 2008, 9(Suppl 9): SII.

8. Hong H, Su Z, Ge W, Shi L, Perkins R, Fang H, Xu J, Chen JJ, Han T and Kaput J, et al: Assessing batch effects of genotype calling 
algorithm BRLMM for the Affymetrix GeneChip Human Mapping $500 \mathrm{~K}$ array set using 270 HapMap samples. $B M C$ Bioinformatics 2008, 9(Suppl 9):SI7.

9. Huan T, Sivachenko AY, Harrison SH and Chen JY: ProteoLens: a visual analytic tool for multi-scale database-driven biological network data mining. BMC Bioinformatics 2008, 9(Suppl 9):S5

10. Kulkarni V, Errami M, Barber R and Garner HR: Exhaustive prediction of disease susceptibility to coding base changes in the human genome. BMC Bioinformatics 2008, 9(Suppl 9):S3.

II. Lee T, Desai VG, Velasco C, Reis RJ and Delongchamp RR: Testing for treatment effects on gene ontology. BMC Bioinformatics 2008, 9(Suppl 9):S20.

12. Mete M, Tang F, Xu X and Yuruk N: A structural approach for finding functional modules from large biological networks. BMC Bioinformatics 2008, 9(Suppl 9):S19.

13. Ptitsyn $A$ : Comprehensive analysis of circadian periodic pattern in plant transcriptome. BMC Bioinformatics 2008, 9(Suppl 9): SI8.

14. Ptitsyn AA, Weil MM and Thamm DH: Systems biology approach to identification of biomarkers for metastatic progression in cancer. BMC Bioinformatics 2008, 9(Suppl 9):S8.

15. Quest D, Dempsey K, Shafiullah M, Bastola D and Ali H: MTAP: the motif tool assessment platform. BMC Bioinformatics 2008, 9(Suppl 9):S6.

16. Rawat A, Seifert GJ and Deng Y: Novel implementation of conditional co-regulation by graph theory to derive coexpressed genes from microarray data. BMC Bioinformatics 2008, 9(Suppl 9):S7.

17. Roux $B$ and Winters-Hilt S: Hybrid MM/SVM structural sensors for stochastic sequential data. BMC Bioinformatics 2008, 9(Suppl 9):SI2.

18. Shi L, Jones WD, Jensen RV, Harris SC, Perkins RG, Goodsaid FM, Guo L, Croner LJ, Boysen C and Fang $\mathrm{H}$, et al: The balance of reproducibility, sensitivity, and specificity of lists of differentially expressed genes in microarray studies. BMC Bioinformatics 2008, 9(Suppl 9):SIO.

19. Su Z, Hong H, Fang H, Shi L, Perkins R and Tong W: Very Important Pool (VIP) genes - an application for microarraybased molecular signatures. BMC Bioinformatics 2008, 9(Suppl 9):S9.

20. Zielinski JS, Bouaynaya N, Schonfeld D and O'Neill W: Timedependent ARMA modeling of genomic sequences. BMC Bioinformatics 2008, 9(Suppl 9):SI4.

21. Centler F, Kaleta C, di Fenizio PS and Dittrich P: Computing chemical organizations in biological networks. Bioinformatics 2008, 24:16||-16|8.

22. Li Y, Agarwal P and Rajagopalan D: A global pathway crosstalk network. Bioinformatics 2008, 24: |442-|447.

23. Mazurie A, Bonchev D, Schwikowski B and Buck GA: Phylogenetic distances are encoded in networks of interacting pathways. Bioinformatics 2008, 24:2579-2585.

24. Vyshemirsky $V$ and Girolami M: BioBayes: a software package for Bayesian inference in systems biology. Bioinformatics 2008 24:1933-1934.

25. Weidemann A, Richter S, Stein M, Sahle S, Gauges R, Gabdoulline R, Surovtsova I, Semmelrock N, Besson B and Rojas I, et al: SYCAMORE - a systems biology computational analysis and modeling research environment. Bioinformatics 2008 , 24: $1463-1464$.

26. Xiong $H$ and Choe $Y$ : Structural systems identification of genetic regulatory networks. Bioinformatics 2008, 24:553-560.

27. Suderman $M$ and Hallett $M$ : Tools for visually exploring biological networks. Bioinformatics 2007, 23:265I-2659.

28. Saeys $Y$, Inza I and Larranaga P: A review of feature selection techniques in bioinformatics. Bioinformatics 2007, 23:2507-25।7.

29. Hibbs MA, Hess DC, Myers CL, Huttenhower C, Li K and Troyanskaya OG: Exploring the functional landscape of gene expression: directed search of large microarray compendia. Bioinformatics 2007, 23:2692-2699.

30. Avila-Campillo I, Drew K, Lin J, Reiss DJ and Bonneau R: BioNetBuilder: automatic integration of biological networks. Bioinformatics 2007, 23:392-393.

31. Schmidt H: SBaddon: high performance simulation for the Systems Biology Toolbox for MATLAB. Bioinformatics 2007, 23:646-647.

32. Schmidt H, Drews G, Vera J and Wolkenhauer O: SBML export interface for the systems biology toolbox for MATLAB. Bioinformatics 2007, 23:1297-1298.

33. Shah AR, Singhal M, Klicker KR, Stephan EG, Wiley HS and Waters KM: Enabling high-throughput data management for systems biology: the Bioinformatics Resource Manager. Bioinformatics 2007, 23:906-909.

34. Li P, Oinn T, Soiland S and Kell DB: Automated manipulation of systems biology models using libSBML within Taverna workflows. Bioinformatics 2008, 24:287-289.

35. Ptitsyn A: Computational analysis of gene expression space associated with metastatic cancer. BMC Bioinformatics 2009, I 0(Suppl II):S6

36. Gao C, Dang $X$, Chen $Y$ and Wilkins $D$ : Graph ranking for exploratory gene data analysis. BMC Bioinformatics 2009, I0(Suppl II):S20.

37. Chowbina SR, Wu X, Zhang F, Li PM, Pandy R, Kasamsetty HN and Chen JY: HPD: An Online Integrated Human Pathway Database Enabling Systems Biology Studies. BMC Bioinformatics 2009, I0(Suppl II ):S5.

38. Zhang L, Berleant D, Ding J, Cao T and Wurtele ES: PathBinder text empirics and automatic extraction of biomolecular interactions. BMC Bioinformatics 2009, I0(Suppl II):SI8.

39. Toyoda T, Mochizuki $\mathrm{Y}$, Player K, Heida N, Kobayashi $\mathrm{N}$ and Sakaki Y: OmicBrowse: a browser of multidimensional omics annotations. Bioinformatics 2007, 23:524-526.

40. Polpitiya AD, Qian WJ, Jaitly N, Petyuk VA, Adkins JN Camp DG 2nd, Anderson GA and Smith RD: DAnTE: a statistical tool for quantitative analysis of -omics data. Bioinformatics 2008, 24: I556-1558.

41. Xia T and Dickerson JA: OmicsViz: Cytoscape plug-in for visualizing omics data across species. Bioinformatics 2008 , 24:2557-2558.

42. Gong L, Owen RP, Gor W, Altman RB and Klein TE: PharmGKB: an integrated resource of pharmacogenomic data and knowledge. Curr Protoc Bioinformatics 2008, Chapter I4(Unit 14): 17

43. Kao HL and Gunsalus KC: Browsing multidimensional molecular networks with the generic network browser $(\mathrm{N}$ Browse). Curr Protoc Bioinformatics 2008, Chapter 9(Unit 9): II.

44. Martens L, Jones $\mathrm{P}$ and Cote R: Using the Proteomics Identifications Database (PRIDE). Curr Protoc Bioinformatics 2008, Chapter I3(Unit I3): I8.

45. Yeung N, Cline MS, Kuchinsky A, Smoot ME and Bader GD: Exploring biological networks with Cytoscape software. Curr Protoc Bioinformatics 2008, Chapter 8(Unit 8): 13 .

46. Pendarvis K, Kumar R, Burgess SC and Nanduri B: An automated proteomic data analysis workflow for mass spectrometry. BMC Bioinformatics 2009, 10(Suppl 9):S17.

47. Mete M, Hennings L, Spencer HJ and Topaloglu U: Automatic Identification of Angiogenesis in Double Stained Images of Liver Tissue. BMC Bioinformatics 2009, I O(SuppI II):SI3.

48. Burkart MF, Wren JD, Herschkowitz JI, Perou CM and Garner HR: Clustering microarray-derived gene lists through implicit literature relationships. Bioinformatics 2007, 23: 1995-2003.

49. Hong $F$ and Breitling $R$ : A comparison of meta-analysis methods for detecting differentially expressed genes in microarray experiments. Bioinformatics 2008, 24:374-382.

50. $\mathrm{Li} \mathrm{H}$ and Zhan $\mathrm{M}$ : Unraveling transcriptional regulatory programs by integrative analysis of microarray and transcription factor binding data. Bioinformatics 2008, 24: I874-1880.

51. Yang D, Li Y, Xiao H, Liu Q, Zhang M, Zhu J, Ma W, Yao C, Wang J and Wang $D$, et al: Gaining confidence in biological interpretation of the microarray data: the functional consistence of the significant GO categories. Bioinformatics 2008, 24:265-27I.

52. Hermans $F$ and Tsiporkova E: Merging microarray cell synchronization experiments through curve alignment. Bioinformatics 2007, 23:e64-70

53. Martin S, Zhang Z, Martino A and Faulon JL: Boolean dynamics of genetic regulatory networks inferred from microarray time series data. Bioinformatics 2007, 23:866-874.

54. Novikov E and Barillot E: Software package for automatic microarray image analysis (MAIA). Bioinformatics 2007, 23:639-640.

55. Royce TE, Rozowsky JS and Gerstein MB: Assessing the need for sequence-based normalization in tiling microarray experiments. Bioinformatics 2007, 23:988-997.

56. Schumacher M, Binder $\mathrm{H}$ and Gerds T: Assessment of survival prediction models based on microarray data. Bioinformatics 2007, 23: 1768-1774

57. Berg van den BHJ, Thanthiriwatte $C$, Manda $P$ and Bridges SM: Comparing gene annotation enrichment tools for functional modeling of agricultural microarray data. BMC Bioinformatics 2009, I O(Suppl I I):S9. 
58. Chavan SS, Bauer MA, Scutari M and Nagarajan R: NATbox: A Network Analysis Toolbox in R. BMC Bioinformatics 2009, IO(Suppl I I):SI4.

59. Perkins $A D$ and Langston MA: Threshold selection in gene coexpression networks using spectral graph theory techniques. BMC Bioinformatics 2009, IO(Suppl II):S4.

60. Li Z, Su Z, Wen Z, Shi L and Chen T: Microarray Platform Consistency Is Revealed by Biologically Functional Analysis of Gene Expression Profiles. BMC Bioinformatics 2009, I0(Suppl I I):SI 2 .

6I. Jankun-Kelly TJ, Lindeman AD and Bridges SM: Exploratory Visual Analysis of Conserved Domains on Multiple Sequence Alignments. BMC Bioinformatics 2009, I O(Suppl III):S7.

62. Xu Z, Zhang D, Hu J, Zhou X, Ye X, Reichel KL, Stewart NR, Syrenne RD, Yang $X$ and Gao $P$, et al: Comparative genome analysis of lignin biosynthesis gene families across the plant kingdom. BMC Bioinformatics 2009, I 0(SuppI I I):S3.

63. Buza TJ, Kumar R, Gresham CR, Burgess SC and McCarthy FM: Facilitating Functional Annotation of Chicken Microarray Data. BMC Bioinformatics 2009, I 0(Suppl I I):S2.

64. Zhou X, Su Z, Sammons RD, Peng Y, Tranel PJ, Stewart N Jr and Yuan JS: Novel Software Package for Cross-Platform Transcriptome Analysis (CPTRA). BMC Bioinformatics 2009, I O(Suppl I I):SI6.

65. Garcia-Reyero N, Adelman IR, Martinović D, Liu L and Denslow ND: Site-specific impacts on gene expression and behavior in fathead minnows (Pimephales promelas) exposed in situ to streams adjacent to sewage treatment plants. BMC Bioinformatics 2009, I O(Suppl II):SII.

66. Chen B and Johnson M: Protein Local 3D Structure Prediction by Super Granule Support Vector Machines (Super GSVM). BMC Bioinformatics 2009, I O(Suppl I I):SI5.

67. Bright L, Swiderski C, Burgess S, Chowdhary B and McCarthy FM: Structural and Functional-annotation of an Equine Whole Genome Oligoarray. BMC Bioinformatics 2009, I O(Suppl I I):S8.

68. Zollanvari A, Cunningham MJ, Braga-Neto $U$ and Dougherty ER: Analysis and Modeling of Time-Course Gene-Expression Profiles from Nanomaterial-Exposed Primary Human Epidermal Keratinocytes. BMC Bioinformatics 2009, I O(SuppI II): SIO.

69. Malone BM, Perkins AD and Bridges SM: Integrating phenotype and gene expression data for predicting gene function. $B M C$ Bioinformatics 2009, I O(SuppI I I):S2 I.
Publish with Bio Med Central and every scientist can read your work free of charge

"BioMed Central will be the most significant development for disseminating the results of biomedical research in our lifetime. "

Sir Paul Nurse, Cancer Research UK

Your research papers will be:

- available free of charge to the entire biomedical community

- peer reviewed and published immediately upon acceptance

- cited in PubMed and archived on PubMed Central

- yours - you keep the copyright
BioMedcentral 